\title{
NICOS POULANTZAS E OS ESTUDOS DE RELAÇÕES INTERNACIONAIS
}

\section{Tatiana Berringer ${ }^{1}$}

\section{Resumo:}

Neste artigo buscaremos comparar criticamente a concepção de Estado utilizada por Hans Morgenthau, autor consagrado pioneiro da teoria realista das relações internacionais, com a teoria de Estado marxista sistematizada por Nicos Poulantzas em Poder Político e Classes Sociais. Defenderemos o conceito marxista de Estado e outro conjunto de problemas para a teoria das relações internacionais.

Palavras-chave: marxismo; realismo; Estado; relações internacionais.

\section{INTRODUÇÃO}

Neste artigo apresentaremos o instrumental teórico de Nicos Poulantzas, especialmente, o conceito de bloco no poder para uso nos estudos de relações internacionais. O nosso objetivo foi demonstrar as aproximações e diferenças entre o realismo e o marxismo, o que fizemos por meio de uma comparação entre o conceito de Estado para o realista Hans Morgenthau e para o marxista Nicos Poulantzas.

Começamos pela a relação entre o realismo e o marxismo nos estudos de relações internacionais.

Como se sabe, o marxismo não ocupou um lugar importante no debate acadêmico de relações internacionais. Os realistas, em geral, buscaram limitar a aplicação do marxismo, tratando-o como mera ideologia que visaria unicamente à construção do socialismo - ou abordando-o como uma interpretação restrita da realidade devido ao fato de tratar exclusivamente das determinações econômicas. É o que se vê nas seguintes passagens extraídas do livro A política entre as nações de Hans Morgenthau (2003):

A teoria marxista repousa sobre toda a convicção, que serve de fundamento para todo o pensamento marxista, de que todos os problemas políticos constituem o reflexo das forças econômicas. (p.103).

\footnotetext{
${ }^{1}$ Doutora em Ciência Política pela Universidade Estadual de Campinas. Integrante do grupo "Neoliberalismo e Relações de Classe no Brasil", vinculado ao Centro de Estudos Marxistas (Cemarx) e do Grupo de Estudos e Pesquisas para Alternativas em Relações Internacionais (GARI) vinculado a Unesp- Franca. Professora de Relações Internacionais na Fundação Armando Alvares Penteado. E-mail: berringer.tatiana@gmail.com
} 
[...] Para Marx e seus partidários, o capitalismo está na raiz da discórdia e da guerra internacional. Afirmam eles que o socialismo internacional acabará com a luta pelo poder no cenário internacional e trará a paz permanente (p.61).

Nesse mesmo sentido, o jurista e cientista político Noberto Bobbio (1988) colocou as seguintes perguntas: existe uma teoria marxista das relações internacionais? Se existe, qual é? E de maneira similar ao que já havia feito com a teoria marxista do Estado (BOBBIO, 1979), o autor respondeu negativamente a tais questões, levantando duas acusações contra o marxismo: (I) o objeto de reflexão de Marx e Engels não foi a guerra, mas a revolução; (II) a teoria leninista do imperialismo é reducionista, pois baseia-se no primado do econômico sobre o político.

Sobre a primeira crítica de Bobbio, pode-se dizer, sem exagero, que o autor reduz, tal como Morghentau, o marxismo a uma ideologia revolucionária. Isso está contido no materialismo histórico, mas não é só isso. $\mathrm{O}$ materialismo histórico é, na verdade, uma teoria da história e, para o que nos interessa mais de perto, uma teoria da sociedade e da política, que articula num todo complexo: forças produtivas sociais e relações de produção, interesses econômicos, lutas de classes em torno da distribuição de recursos e de poder, relações de dominação, etc. Nesse instrumental aberto, o marxismo conjuga a análise econômica com a análise da estrutura jurídicopolítica e das ideologias atuantes. Essa junção permite pensar tanto a reprodução das relações sociais em suas distintas esferas (econômica, política e ideológica), como também as formas de superação dessas estruturas por ação dos agentes — as classes sociais e suas organizações políticas (ALTHUSSER, 1999).

Marx partia do pressuposto de que para transformar uma realidade concreta é preciso conhecê-la com profundidade. E foi disso que se ocupou em suas obras: um estudo minucioso a respeito da forma de organização e de reprodução da sociedade capitalista. Para o filósofo francês Louis Althusser (1999), a contribuição de Marx e Engels para as ciências sociais foi tão profunda e revolucionária quanto às descobertas de Tales na matemática e de Galileu na física. Inaugurou-se uma verdadeira ciência da história: um continente científico novo.

No campo próprio das Relações Internacionais, consideramos que o marxismo é capaz de explicar não somente as guerras, mas todas as relações subjacentes a tal episódio extremo. Sem o estudo das relações políticas, econômicas e sociais entre os Estados, bem como da relação entre o que se reproduz no interior de uma formação social e seu reflexo no cenário internacional, a teoria das relações internacionais aí sim fica restrita e limitada. As tradições diplomáticas, o quadro institucional e as mudanças em política externa para que sejam compreendidas devem se inserir na relação entre as distintas classes sociais tanto no âmbito doméstico como internacional.

Fred Halliday (1999), um importante pensador das relações internacionais, afirma que o marxismo desenvolveu um trabalho reconhecido e analiticamente fértil na sociologia, na história e em outras ciências sociais, e nos estudos de relações internacionais ainda há um potencial enorme a ser explorado. 
Embora poucos marxistas tenham se dedicado a estudar sistematicamente as guerras, pode-se dizer que o debate sobre o "Imperialismo e a guerra" entre Vladimir I. Lênin (1982) e Karl Kaustky (2008) precedeu o debate entre idealistas versus realistas após a Primeira Guerra Mundial².

$\mathrm{Na}$ realidade, esse debate que se desenvolveu no seio do movimento socialista internacional é muito próximo às discussões que estiveram na origem dos estudos acadêmicos de relações internacionais no início do século XX. Podemos com segurança dizer, a despeito da diferença dos argumentos mobilizados pelos acadêmicos, que Lênin estava muito próximo da posição defendida pelos realistas enquanto Kaustky acabava por se aproximar dos idealistas.

Por isso, diante da acusação de Bobbio acerca do reducionismo econômico de Lênin, elencamos cinco pressupostos apresentados em Imperialismo: a fase superior do capitalismo que demonstram não só o caráter clássico da obra — cuja contribuição não se esgotou com o passar do tempo e as mudanças históricas havidas até aqui —, mas também como o marxismo não se reduziu à análise econômica para refletir sobre as relações internacionais. Vejamos o que Lênin pressupõe para analisá-las.

Há um desenvolvimento desigual entre as nações ligado à relação de dominação que se realiza entre os Estados imperialistas e as colônias e/ou Estados dependentes.

Há uma disputa entre os Estados imperialistas ligada ao domínio por mercados, matérias-primas, e ao controle de territórios e recursos naturais das colônias e dos Estados dependentes.

É impossível haver paz enquanto existir sociedades cindidas em classes sociais.

O "[...] verdadeiro caráter de classe de uma guerra não se encontrará, naturalmente, na sua história diplomática, mas na análise da situação objectiva das classes dirigentes de todas as potências beligerantes (1982, p.581)".

Há uma relação de influência mútua entre as guerras civis e o imperialismo, ou dito de outra forma, a política doméstica e a política externa de um Estado são entrelaçadas.

Ainda vale dizer que para Lênin o imperialismo não corresponde apenas a atual fase do capitalismo. Vejamos o trecho a seguir:

A política colonial e o imperialismo existiam já antes da fase mais recente do capitalismo e até mesmo antes do capitalismo. Roma, baseada na escravatura, manteve uma política colonial e exerceu o imperialismo. Mas as considerações "gerais" sobre o imperialismo, que esquecem ou relegam para o segundo plano as diferenças radicais entre as transformações econômico-sociais, degeneram inevitavelmente em trivialidades ocas e jactâncias, tais como a de comparar a "a grande Roma como a Grã-bretanha". Mesmo a política colonial capitalista das fases

\footnotetext{
${ }^{2}$ O texto de Kaustky “O Imperialismo e a guerra” foi escrito em 1914 e o "Imperialismo: fase superior do capitalismo" de Lênin em 1917. 
anteriores do capitalismo é essencialmente diferente da política colonial do capital financeiro (Lênin, 1982, p. 637).

É verdade que a sua preocupação central era a de identificar a particularidade do imperialismo sob a hegemonia do capital financeiro. Apesar disso, o texto é recheado de elementos que vão muito além de uma simples análise de conjuntura.

Contra a ideia de "superimperialismo" de Kaustky (2008) segundo a qual os monopólios poderiam levar a constituição de uma "Santa Aliança" entre os Estados imperialistas de tal sorte que a corrida armamentista chegaria ao fim, Lênin (1982, p.664-665) disse:

Sob o capitalismo não se concebe outro fundamento para a partilha das esferas de influência, dos interesses, das colônias, etc., além da força de que participa da divisão, a força econômica geral, financeira e militar, etc. E a força dos que participam da divisão não se modifica de forma idêntica, visto que sob o capitalismo é impossível o desenvolvimento igual das diferentes empresas, trusts, ramos industriais e países. [...]

[...] Por isso as alianças "interimperialistas" ou "ultra imperialistas" no mundo real capitalista e não na vulgar fantasia filistina dos padres ingleses ou do "marxista" alemão Kaustky — seja qual for a sua forma; coligação imperialista contra outra coligação imperialista, ou uma aliança geral de todas as potências imperialistas —, só podem ser, inevitavelmente, "tréguas" entre guerras. As alianças pacíficas preparam as guerras, conciliando-as mutuamente, gerando uma sucessão de formas de luta pacífica e não pacífica sobre uma mesma base de vínculos imperialistas e de relações recíprocas entre a economia e a política mundiais.

Esses argumentos indicam, grosso modo, a proximidade de Lênin com a abordagem realista de relações internacionais. A convergência entre o marxismo e o realismo foi reconhecida por E. Carr (2001). O autor de Os Vinte anos de crise é o responsável por introduzir o debate entre realismo e idealismo nos estudos de relações internacionais no início do século XX. Segundo ele, o marxismo e o realismo tratam a política tal como ela é conflituosa. Por isso, ambos se contrapõem ao idealismo kantiano.

Waever (1996) segue a mesma linha de Carr (2001) para detalhar o que ele chamou de debate "interparadigmático" entre realismo, liberalismo e marxismo, que teria ocorrido nas décadas de 1970 e 1980.

Apesar dessas aproximações, é importante frisar que os marxistas entendem que a origem dos conflitos entre os Estados repousa em seu caráter de classe. Por isso, ainda que existam pontos de contato entre o realismo e o marxismo, não se pode perder de vista que são correntes teóricas bem diferentes.

O realismo tornou-se um arcabouço teórico muito utilizado nos estudos de relações internacionais. Os autores desta corrente tomaram como base a teoria política clássica, em especial, Maquiavel e Hobbes, para pensar a política internacional. As principais assertivas desta corrente são: (I) a centralidade do Estado; (II) a permanência dos conflitos no ambiente internacional.

Na verdade, tanto para os realistas quanto para os marxistas o Estado é a categoria central das relações internacionais. Mas, como salientou Halliday (1999, p.94) as concepções são bastante distintas. 
As correntes que criticaram o realismo - em especial o neoliberalismo (Keohane e Nye, 1973) apoiaram-se, em sua maioria, no argumento da redução do papel do Estado no contexto da "globalização neoliberal" e da emergência dos chamados novos atores das relações internacionais - corporações transnacionais, ONGs, organizações internacionais, movimentos sociais, migrações internacionais - sem se preocuparem com a definição do conceito de Estado. O que nos distingue destes críticos é que o nosso objetivo não foi discutir o peso do Estado nas relações internacionais, visto que não divergimos da sua centralidade. Mas, antes disso, o nosso objetivo foi o apresentar o instrumental teórico sistematizado por Nicos Poulantzas como alternativa para o estudo das relações internacionais e para as análises de política externa.

É importante dizer que apesar de o Estado ser a categoria analítica fundamental das teorias realistas de relações internacionais ${ }^{3}$, não encontramos nos autores realistas, uma definição clara e precisa acerca do Estado. Parece que os adeptos da corrente realista supõem que o leitor saiba de antemão do que se trata, pois o Estado aparece apenas em "estado prático", quer dizer, na forma de uma categoria empírica. Segundo Fred Halliday (1999, p.91):

Na verdade, é paradoxal que um conceito tão central a toda a disciplina tenha escapado de uma
discussão como esse o fez. Podem ser encontradas muitas discussões sobre a guerra, a soberania,
as instituições e assim por diante, mas pode-se procurar em vão nos livros por discussões
semelhantes sobre o Estado. Os teóricos das relações internacionais supõem que nós sabemos o
que ele é: Bull, que é uma comunidade política; Waltz, que é, na prática, uma co-extensão da
nação. Como um todo, as relaçōes internacionais consideram como dada uma definição
especifica: o que se pode classificar de totalidade nacional-territorial. Assim o Estado (Grã-
Bretanha, Rússia, América, etc.) abrange em forma conceitual o que é percebido visivelmente no
mapa político - o país como um todo e tudo que está dentro dele: o território, o governo, o
povo e a sociedade.

Em nossa dissertação de mestrado realizamos uma comparação entre o marxismo e o realismo no tocante ao conceito de Estado e a função que ele desempenha nas relações internacionais. Em síntese, nosso trabalho concentrou-se em: (I) sistematizar o que o realismo entende por Estado; (II) apresentar o conceito de Estado marxista e o de bloco no poder tal como desenvolvidos por Nicos Poulantzas, bem como apontar a possibilidade de uso desse sistema teórico para os estudos de relações internacionais.

Um dos motivos que nos levaram a escolher Poulantzas se deve ao fato de que sua teoria de Estado responde diretamente às críticas feitas pelos realistas ao marxismo. Poulantzas não entende, como pressupõem os realistas, que a política seja um reflexo das forças econômicas. Em Poder Político e Classes Sociais seu objeto de estudo é o "político", enquanto complexo de estruturas, instituições e práticas distintivas do modo de produção capitalista. Poulantzas mantém na sua explicação o primado da determinação econômica, atribuindo

\footnotetext{
${ }^{3}$ Destacamos que o Estado se mantém enquanto categoria analítica fundamental no neorrealismo, versão renovada do realismo. Segundo Waltz (1979), o principal autor da abordagem neorrealista, o cenário internacional aproximar-se-ia do modelo metafórico de uma sinuca, na qual os Estados seriam bolas de bilhar, maciças e indivisíveis, colidindo em busca de segurança.
} 
simultaneamente peso para as determinações políticas, ideológicas e conjunturais. E sua análise não se centra na transição ao socialismo: tal autor foi acusado por muitos dos seus pares por ter centrado seus estudos apenas na compreensão da reprodução do modo de produção capitalista, deixando de lado as questões relativas ao processo de transição socialista.

A possibilidade do uso do instrumental poulantziano para os estudos de relações internacionais foi apontada por dois importantes defensores do realismo, o já citado Noberto Bobbio (1988) e Stephan Krasner (1978). Para ambos, o conceito de autonomia relativa do Estado apresentado por Nicos Poulantzas, se utilizado nos estudos de relações internacionais, poderia de fato trazer uma maior capacidade explicativa do que a visão instrumentalista de Estado defendida por muitos marxistas ${ }^{4}$. A ideia de autonomia relativa abre a possibilidade de uma análise mais profunda da relação entre o Estado e as classes dominantes.

Vale dizer que Rosenberg (2001), Linklater (2001b) e Callinicos (2007) também empreenderam uma comparação entre realismo e marxismo com foco no conceito de Estado. No entanto, tomaram como base concepções de Estado distintas àquela que utilizamos.

A sistematização teórica de Poulantzas permite extrair elementos para a caracterização dos vários tipos de Estado - escravista, feudalista e capitalista. No geral, o Estado é uma instituição que organiza a dominação de um conjunto de classes sociais sobre outras, tendo, assim, por função principal a reprodução da totalidade social. (Saes, 1985). Para Poulantzas, o Estado capitalista se distingue dos demais tipos de Estado porque a dominação política de classe não se mostra visivelmente presente em suas instituições. O Estado se apresenta, pois, como um Estado nacional e popular, ocultando as contradições de classe presentes no interior da formação social que ele organiza e representa. Suas instituições são organizadas em torno dos princípios de liberdade e igualdade dos cidadãos, bases para a soberania e legitimidade desse Estado. "O Estado capitalista moderno apresenta-se, assim, como encarnando o interesse geral de toda a sociedade, como substancializando a vontade desse 'corpo político' que seria a nação. (POULANTZAS, 1977, p. 119)".

Já nos Estados pré-capitalistas, as instituições estatais eram monopólio dos membros da classe dominante e o direito não ocultava o caráter de exploração nas relações de produção: era um direito essencialmente desigual. O Estado escravista negava a personalidade jurídica ao escravo, pois o colocava como propriedade do senhor. O Estado feudal declarava ao servo a capacidade de praticar atos, que por sua vez se materializavam em obrigações com o senhor feudal. No feudalismo, a divisão da sociedade em estamentos e ordens, na prática, correspondia à desigualdade do estatuto jurídico entre servos e senhores. Os tribunais eram senhoriais, compostos por nobres e pelo clero. Os postos no exército e os cargos estatais também eram

\footnotetext{
${ }^{4}$ Por exemplo, Ralph Miliband (1972).
} 
preenchidos pelo critério estamental ou eram vendidos como títulos familiares. Era, portanto, vedada a participação servil no aparelho de Estado. "[...] A ideologia jurídica feudal não oculta a exploração, ela a apresenta como necessária. (BOITO, 2007, p.71)”.

Segundo Poulantzas (1977), o Estado capitalista exerce a função ideológica de unidade do "povo nação" enquanto, na realidade, ele organiza a hegemonia de uma ou mais frações e as expõe como interesses gerais da nação. A relação entre o território e a comunidade nacional arquiteta ideologicamente a nação, e recobre as contradições presentes nas relações de produção capitalista.

O Estado é o representante oficial da sociedade, "[...] lugar onde se decifra a unidade de uma formação [social]”. (POULANTZAS, 1977, p.47). Para Poulantzas, a formação social é uma combinação concreta de vários modos de produção "puros" com a dominância de um modo sobre os demais. Essa combinação é uma realidade complexa marcada por um desenvolvimento desigual. Em uma mesma formação social podem conviver diversas formas de produção - tipos pré-capitalistas, políticas patrimonialistas e relações capitalistas - com a dominância de um. Assim como podem conviver diversas nacionalidades que são consubstancializadas na ideologia nacional. E é sobre a formação social que o marxismo desenvolve suas análises da realidade concreta. O Estado e o modo de produção são, portanto, conceitos abstrato-formais, que abrangem as relações de produção, políticas e ideológicas. Mas os "modos de produção" só existem e se reproduzem em formações sociais determinadas historicamente.

A estrutura jurídico-política do Estado capitalista é formada pelo direito capitalista e pelo burocratismo. As relações de produção dependem destas estruturas, que por seu turno exercem a duplo efeito de isolamento constituição de indivíduos juridicamente atomizados - e representação da unidade — criação do corpo político "povo nação". Através deles o Estado cumpre a função de desorganizar as classes dominadas enquanto organiza as classes dominantes.

Já para Morgenthau (2003) o Estado-nação é apresentado apenas como ilustração da distinção entre a política doméstica e as relações internacionais. Ou seja, para definir as relações internacionais, a descrição do ambiente nacional foi utilizada como padrão comparativo. De um lado, há uma sociedade governada por leis e por um aparato coercitivo, na qual existe ordem e paz social, e, de outro lado, há uma sociedade anárquica, isto, é: sem um poder central. Por isso, o sistema internacional caracteriza-se pela permanência do estado de natureza hobessiano (luta de todos contra todos).

O Estado-nação, para esse realista, é uma organização compulsória da sociedade. É uma instituição que permite a continuidade legal da nação e que dispõe dos órgãos institucionais necessários para a implementação das leis e das mudanças sociais. O aparato estatal ocupa-se em manter o status quo ao qual ele deve a sua existência. Para isso, utiliza-se do poder e da força a fim de coagir as eventuais perturbações à ordem que possam emergir no seio da sociedade nacional (MORGENTHAU, 2003). 
Segundo Morgenthau (2003), os indivíduos aceitam o Estado e defendem a nação, pois a enxergam como fonte de proteção em relação ao inimigo e como um poder capaz de manter a paz e a ordem social. Os indivíduos são leais à nação devido ao medo de que ela seja destruída por forças internas (indivíduos) e externas (nações) $^{5}$. A soberania do Estado - unidade nacional - é, portanto, a autoridade suprema e a entidade recebedora da lealdade dos indivíduos, uma vez que os diferentes grupos submetem seus reclamos aos canais institucionais do Estado com a esperança de que este atenda de maneira justa e equânime aos interesses divergentes que se fazem presentes no interior da sociedade nacional. Diz Morgenthau:

Dentro de uma nação, a paz entre os grupos sociais repousa em um alicerce duplo: a falta de
desejo dos membros da sociedade de quebrar a paz e sua incapacidade de conseguir fazê-lo,
caso essa fosse a sua inclinação. Os indivíduos não terão como quebrar a paz se um poder
avassalador tornar essa tentativa um empreendimento fadado ao fracasso. E são duas as
condições para que eles não tenham o menor desejo de romper a paz. De um lado, é
necessário que eles sintam para com a sociedade como um todo uma lealdade superior à
que eles poderiam ter com qualquer parte dela. Em segundo lugar, eles precisam ter motivos
para esperar que a sociedade lhes propicie certo grau de justiça, mediante a satisfação
mínima de suas demandas. A presença de três condições - força avassaladora, lealdades
supra seccionais, expectativa de justiça - torna possível a manutenção da justiça no interior
das nações. A ausência dessas condições no cenário internacional evoca sempre o perigo da
guerra (Morgenthau, 2003, p.906-907).

Para o realismo, a comunidade nacional mesmo sendo composta por diversos grupos de interesse, unifica-se nacionalmente. A nação é uma abstração de indivíduos que compartilham simbologias como: língua, costumes, história, heróis, etc. Essas simbologias, por sua vez, constroem um imaginário coletivo que vem a ser a identidade nacional.

O conceito de Estado utilizado por Morgenthau diferencia-se, segundo o autor, tanto da doutrina liberal do século XIX quanto do marxismo. Para a doutrina liberal, a violência organizada da sociedade era completamente neutra, ao passo que, para o marxismo, é uma ferramenta com a qual a classe dominante mantém o seu domínio sobre as classes exploradas. Já para Morgenthau, o emprego da força estatal não é completamente neutro, pois o Estado está de fato a serviço do status quo sob o qual emergiu (MORGENTHAU, 2003, p.913914).

Manter a coesão social é, portanto, um ponto de contato entre o realismo e o marxismo. No entanto, diferentemente do marxismo, Morgenthau, assim como o pluralismo na ciência política, não vê dominação de classe, mas grupos de interesses diversos, como: grupos étnicos, culturais, religiosos e também econômicos.

Já para o marxismo, embora na esfera da troca apareçam indivíduos livres e iguais, na estrutura produtiva os agentes ocupam posições contraditórias definidas pela divisão social do trabalho, na qual há apropriação privada de trabalho e a sujeição dos produtores diretos a um processo produtivo coletivo. É dizer, o momento da

\footnotetext{
${ }^{5}$ Neste ponto a inspiração hobbesiana é evidente.
} 
produção social, certamente o mais importante em toda a vida individual e social, é atravessado por relações de exploração e domínio. Ao mesmo tempo em que todos integram a mesma comunidade nacional, adquirem interesses econômicos, formas de consciência e projetos políticos contraditórios e, em certas circunstâncias, antagônicos.

Por isso, a nação corresponde ao efeito ideológico de representação da unidade do "povo nação", a qual alude a uma realidade vivida pelos indivíduos atomizados dentro de um determinado território. Os capitalistas ao vivenciarem a concorrência do mercado, encontram dificuldades para se auto organizarem enquanto classe social distinta. Por isso, cabe ao Estado organizar o bloco no poder - a unidade contraditória entre as classes e frações de classe burguesas.

Em suma, tanto para o marxismo quanto para o realismo, a função social do Estado é unificar a sociedade nacional. A diferença é que para Morgenthau essa unidade se dá em torno do interesse nacional - do poder do Estado no cenário internacional -, enquanto que para Poulantzas, a unidade do "povo nação" se dá em torno dos interesses das classes dominantes.

Do ponto de vista marxista, a definição de Estado de Morgenthau é superficial e enganosa, pois trata o Estado como ele aparenta ser e não como de fato é. O monopólio legítimo do uso da força e a garantia da proteção e da segurança do território nacional não é a única função que o Estado desempenha. Na realidade, é sob estes argumentos que o Estado se legitima e, com isso, oculta a dominação de classe e a natureza das políticas governamentais. Através do discurso de garantia do Estado democrático de direito e defesa da soberania nacional é que o Estado se vale do uso da força para reprimir e neutralizar as ações coletivas, ou melhor, que ele isola as classes sociais em indivíduos livres e iguais, como cidadãos de uma mesma nação.

Para Morgenthau (2003), a institucionalidade do Estado resume-se à burocracia civil e militar. Esses funcionários representam o Estado na arena internacional e agem de acordo com as regras legais e racionais. Demonstrando sua filiação às teorias das elites, o realista defende que na cena internacional somente alguns indivíduos são aptos a representar o Estado, pois as massas são irracionais e não conseguem pensar além da disjuntiva bem versus mal. Assim, cabem aos estadistas as decisões sobre política externa. O povo, ou melhor, as massas amorfas, é incapaz de pensar e formular sobre a política, por isso, só participam da política através das eleições, momento no qual decide e escolhe os governantes. Sob esse enquadramento, a sociedade divide-se não entre classes dominantes e dominadas, cuja relação é mediada por representações políticas, mas entre governados e governantes indistintamente 6.

\footnotetext{
${ }^{6}$ Contraditoriamente, como vimos acima, na política doméstica, a sociedade é formada por diversidade de grupos que depositam uma expectativa de justiça com a qual esperam ter a possibilidade de apresentar suas reivindicações aos mecanismos de controle
} vol.07, no. 02, Rio de Janeiro, 2014.pp. 433-452 
Também para Poulantzas (1977) a institucionalidade estatal é formada pela burocracia civil e militar, e, eventualmente, pelo parlamento ${ }^{7}$. No entanto, tal autor trata o burocratismo como uma forma de organização do aparato estatal, derivada do direito burguês e que é funcional ao modo de produção capitalista. A burocracia "[...] representa uma organização hierárquica, por delegação de poder, do aparelho de Estado, quem tem efeitos particulares sobre o seu funcionamento." (POULANTZAS, 1977, p.346). A burocracia está associada à universalidade das instituições do Estado, ou melhor, ao fato de que as instituições estatais podem ser acessadas e integradas por todos os cidadãos.

\section{[...] A burocracia pode representar, no quadro dessa legitimidade, a unidade política do povo nação; apresenta-se - e pode apresentar-se - como um corpo — neutro, encarnando o interesse geral, e cujo funcionamento político a respeito das classes é assim sistematicamente mascarado (POULANTZAS, 1977, p. 344).}

Para o marxismo, o modo de produção capitalista divide a sociedade entre produtores e não produtores (classe trabalhadora e burguesia), e não entre governados e governantes ou grupos de interesses. A relação entre a burguesia e a classe trabalhadora é uma relação de dominação sob a qual há uma apropriação do sobre-trabalho do produtor pelo proprietário dos meios de produção. O Estado é o responsável pela manutenção das relações de produção —o interesse político das classes dominantes — sem que seja necessário, para tanto, intervir diretamente sobre a produção. No modo de produção capitalista, o Estado é dirigido pela classe dominante sem que ela ocupe pessoalmente suas instituições. É neste ponto que se encontra a ideia de autonomia relativa do Estado capitalista defendida por Poulantzas (1977).

Segundo esse marxista, o aparato estatal é composto por uma categoria social - a burocracia - e o poder de Estado propriamente dito cabe à classe ou fração de classe dominante do bloco no poder. A burocracia civil e militar é uma categoria social ${ }^{8}$ específica que serve aos interesses da classe dominante, não em virtude da sua origem de classe, mas, porque realiza o papel objetivo desse Estado. Esse papel corresponde aos interesses políticos da classe dominante, quais sejam: a manutenção da estrutura das relações de produção e a organização de um bloco de classes no poder, dentro do qual são atendidos os interesses econômicos das frações e classes segundo uma hierarquia interna de poder. (POULANTZAS, 1975, p.21).

democrático: eleições, opinião pública, parlamentos, etc. Inferimos, portanto, que Morgenthau utiliza-se de correntes teóricas incompatíveis como a teoria das elites e o pluralismo.

${ }^{7}$ Colocamos a eventualidade do parlamento, pois, para Poulantzas, o regime e a forma de governo estão sujeitos à luta de classes no interior da formação social nacional. O tipo de Estado burguês pode ser democrático ou ditatorial, parlamentar, monárquico, bipartidário, etc. Quer dizer, a forma ditatorial que pode assumir o Estado não lhe retira o caráter burguês. Por menores que sejam as liberdades políticas toleradas, o direito de propriedade, a circulação mercantil e o assalariamento seguem invariavelmente preservados.

${ }^{8} \mathrm{O}$ marxismo distingue classes sociais de categoria sociais, camadas e frações de classe. Leva em conta as diferenciações econômicas e o papel particular das relações políticas e ideológicas que cada uma desempenha, sem abandonar seu pertencimento de classe. Dependendo da conjuntura concreta, essas categorias, camadas ou frações podem se tornar forças sociais e então influir na mudança da realidade. 
[...] pode-se dizer que o estado capitalista serve melhor aos interesses da classe burguesa exactamente quando os membros desta classe não participam directamente no aparelho de Estado, quer dizer, quando a classe dominante não é a classe politicamente governante (POULANTZAS 1975, p.20).

O Estado é um aparelho dirigido pela classe ou fração hegemônica do bloco no poder: esta é que detém o poder político na relação com os dominados, poder exercido através do Estado. A este cabe a organização do próprio bloco através do equilíbrio instável de compromisso entre classes e frações de classe. Na formação do equilibrio instável de compromissos no interior do bloco no poder, entra em jogo também o atendimento às reivindicações das classes dominadas segundo a relação de forças em cada momento.

Poulantzas se apropria do conceito de hegemonia formulado por Gramsci, e o utiliza para interpretar a luta e as práticas políticas das classes dominantes. Para ele, o Estado capitalista é um “[...] Estado com direção hegemônica de classe". (POULANTZAS, 1977, p.133, itálico do autor). O conceito de hegemonia indica a constituição dos interesses políticos das classes dominantes através do Estado. Entre essas classes e frações, uma delas exerce a dominação hegemônica no interior do bloco quando seus interesses são prioritariamente atendidos na política social e econômica de Estado. Apesar disso, essa política se apresenta como a representação do interesse geral do povo nação em determinada conjuntura histórica:

[...] A classe hegemônica é aquela que em si concentra, ao nível político, a dupla função de representar o interesse geral do povo nação e de manter uma dominância específica entre as classes e frações dominantes; e isto, na sua relação particular com o Estado capitalista. (POULANTZAS, 1977, p.137).

Por isso, a tarefa do pesquisador é desvendar na política social e econômica de Estado em cada conjuntura - e na política externa, é claro —, a relação entre as diferentes medidas e posições assumidas pelos representantes políticos e agentes da burocracia, de um lado, e, de outro, a hierarquia no interior do bloco no poder e sua tensão constante com as classes dominadas.

E, com efeito, a relação do Estado com o conjunto de classes dominadas também é entendida a partir da autonomia relativa. Poulantzas (1977) defende que o Estado capitalista atende constantemente interesses econômicos das classes dominadas, desde que num determinado nível ou, nas palavras de Poulantzas, abaixo de certo limite. Pois, o objetivo último do Estado é garantir a manutenção dos interesses políticos da classe dominante, ou melhor, a manutenção do modo de produção capitalista. Vale citar o autor:

A característica, própria do Estado capitalista, de representar o interesse geral de um conjunto nacional-popular não constitui assim uma simples mistificação enganadora, no sentido de que esse Estado pode efetivamente satisfazer, abaixo desses limites, certos interesses econômicos de certas classes dominadas; ainda mais: pode fazê-lo, sem que, no entanto, o poder político seja atingido. (POULANTZAS, 1977, p.187).

Nesse diapasão, o Estado organiza as classes dominantes enquanto mantém as classes dominadas desorganizadas. No entanto, as classes dominadas não são irracionais e iludidas como defende Morgenthau. A 
ideologia dominante, para Poulantzas, alude a uma realidade vivida pela sociedade, sem que se possa dizer que haja uma falsa consciência das massas.

A definição de identidade nacional, por seu turno, corresponde o poulantziano Lucio Flávio de Almeida (1995) chama de nacionismo. Trata-se, segundo o autor, da ideologia dominante cujo objetivo é a legitimação do papel do Estado e a ocultação da dominação de classe no interior da formação social. A nação é uma ideologia cuja função é manter a ordem social no interior do território estatal. Como Almeida (1995) tratou, o nacionismo é a expressão do sentimento de pertencimento à comunidade nacional: é o efeito ideológico de representação da unidade da estrutura jurídico-política do modo de produção capitalista, o qual está sujeito à luta de classes. A ideologia nacional depende da fração ou classe hegemônica podendo assumir diferentes configurações em função da conjuntura política e das forças sociais?.

A nação, portanto, é uma expressão típica do modo de produção capitalista. O Estado capitalista, através da estrutura jurídico-política constrói a ideia de nação, amparado muitas vezes no conjunto de símbolos (língua, cultura, etnia) que contribuem para a representação da unidade. De acordo com Almeida (1995, p.48):

[...] O Estado capitalista funciona de um modo nacional. Suas estruturas e a ideologia que a ele se articula produzem a nação. Mas a relação se apresenta invertida: o Estado aparece como consequência da nação, como se fosse o resultado último e acabado de um desabrochar do ser nacional que, só então, por intermédio do Estado, se autodetermina e expressa sua soberania.

Lembremos que, para Poulantzas, a ideologia dominante não é reduzida a uma falsa consciência diante da qual o discurso da burguesia engana o trabalhador. Pelo contrário, a ideologia alude à realidade vivida pelos cidadãos e produz uma ilusão na qual os indivíduos se reconhecem como membros iguais da sociedade. Nas palavras de Almeida (1995, p.50):

[a ideologia nacional] remete — como já foi visto — às relações ideológicas fundamentais do capitalismo, pois se vincula fortemente à legitimidade do tipo burguês de Estado. Neste sentido, pode-se afirmar que em qualquer formação social capitalista tem existido, em épocas - normais —, algum tipo de nacionismo, ou seja, reprodução da ideologia nacional. Trata-se de um elenco de práticas que expressam e reproduzem o sentimento de que todos os agentes da formação social constituem, em alguma dimensão, uma coletividade singular de indivíduos essencialmente iguais.

Morgenthau (2003) afirmou que o nacionalismo moderno emergiu das guerras napoleônicas, ou seja, após as revoluções burguesas. Apesar disso, o autor não admite a relação entre Estado, nação e capitalismo. Lembramos que as revoluções burguesas do século XVIII e XIX, dentre as quais as guerras napoleônicas, foram determinantes para a formação do Estado burguês. Morgenthau desconsidera que esse tipo de Estado esteja relacionado ao modo de produção capitalista.

\footnotetext{
${ }^{9}$ Lembramos que a revolução socialista pode em muitos casos ter caráter nacional.
} 
Enfim, a partir da concepção de que os Estados têm a função de manter a coesão das formações sociais divididas em classes antagônicas, para o que interessa à teoria de relações internacionais, destacamos que pertencer a um Estado, ser cidadão brasileiro, francês ou indiano não se refere simplesmente ao território habitado e à língua falada, mas diz respeito às determinações econômicas, políticas e ideológicas daquela formação social.

Para a corrente realista, o objetivo da política externa é o poder, concebido como "interesse nacional". As relações entre os Estados são de natureza estritamente política, isto é, visam unicamente ao poder. Nesse sentido, a política externa é definida a partir de três estratégias que buscam, respectivamente, aumentar, conservar ou demonstrar o poder. São elas: (I) imperialismo — alterar a relação de poder do sistema mundial; (II) status quo — conservar ou reaver a posição outrora ocupada pela nação na distribuição de poder entre as nações; (III) política de prestígio - demonstrar este poder através de cerimoniais diplomáticos, exibições das tropas, arsenais, etc.

Já para o marxismo, o Estado defende o interesse do bloco no poder, velado pelo discurso enganoso do interesse nacional. Os realistas, por seu turno, defendem que os Estados lutam por poder e as políticas externas correspondem aos interesses nacionais de cada Estado como se tal poder fosse real. Inferimos, portanto, que Morgenthau ignora as bases sociais contraditórias sobre as quais se assenta o Estado e o concebe como uma entidade homogênea. A ideia de "interesse nacional" defendida por Morgenthau não revela os interesses e as causas dos conflitos, nem tampouco a natureza das atividades diplomáticas, comerciais e bélicas.

Segundo o marxismo, as tomadas de decisão não correspondem aos interesses de todas as classes sociais: regra geral, a nação se divide diante de uma disputa externa. A política externa aparenta representar o interesse geral da nação, mas, na realidade, corresponde aos interesses do bloco no poder. Conforme as palavras de Oswaldo Amaral (2007, p.130):

Ao qualificar o Estado como um agente racional que busca sempre o "interesse nacional", a teoria realista trata, mesmo que de maneira indireta, o Estado enquanto encarnação da vontade geral frente aos indivíduos iguais e isolados, contribuindo assim para que os agentes da produção não percebam, na sua luta econômica, as relações de classes [...]. Essa característica da teoria realista torna-se ainda mais evidente quando esta enfatiza o sistema internacional e se recusa a observar os fatores internos que determinam o "interesse nacional" defendido pelo Estado, encobrindo definitivamente o seu caráter de classe.

Para nós, seguindo a contribuição de Nicos Poulantzas, a política externa deve ser interpretada a partir do bloco no poder. Com isso, desmistifica-se a ideia de representação do "interesse geral" da sociedade no cenário internacional: o Estado não representa os interesses do povo nação, mas sim, o interesse das classes dominantes, ou melhor, do bloco no poder. A política externa não é, portanto, uma política de Estado autônoma em relação às classes sociais e aos governos. Ela é determinada pela fração hegemônica do bloco no poder e é permeada pela contradição entre as classes e frações de classe. É evidente que a burocracia, a tradição diplomática e seus objetivos 
influem nesse processo. Mas é preciso captar essas determinações no bojo da relação com os conflitos de classes no interior das formações sociais e entre as classes das formações dominantes com relação às classes das formações sociais dependentes.

Vejamos as diferenças entre o realismo e o marxismo no quadro abaixo:

\begin{tabular}{|l|l|l|}
\hline Pontos & Realismo & Marxismo \\
\hline Política externa & Interesse nacional & Interesses do Bloco no Poder \\
\hline Agentes da política externa & Diplomata e soldado & $\begin{array}{l}\text { Diplomata, soldado, ministros } \\
\text { (indústria, } \\
\text { desenvolvimento, meio ambiente, } \\
\text { etc.) e chefes de governo. }\end{array}$ \\
\hline Relações Internacionais & Disputa e alianças de poder entre \\
as nações soberanas & $\begin{array}{l}\text { Disputa (desigual), alianças e } \\
\text { interpenetrações entre os blocos no } \\
\text { poder de diferentes Estados }\end{array}$ \\
\hline Guerra & A política nacional por outros \\
meios - Clausewitz & $\begin{array}{l}\text { A política de classes por outros } \\
\text { meios - Lênin e Bukharin }\end{array}$ \\
\hline
\end{tabular}

Tanto para o marxismo quanto para o realismo, a guerra é a política por outros meios. Ou seja, ambos partem da ideia de que a política é conflituosa, mas, para o realismo o conflito repousa na natureza humana que segundo Morgenthau é má, e para os marxistas os conflitos têm natureza de classe. Nesse sentido, para marxismo a guerra é a política de classes por outros meios e para o realismo é a política nacional por outros meios. Ou seja, o que motiva a entrada em um conflito para o realismo é a busca pelo prestígio e pelo poder, enquanto para o marxismo a política é determinada pelos interesses das classes dominantes - do bloco no poder - e as disputas e alianças são, na maioria das vezes, conflitos e acordos entre classes dominantes dos diferentes Estados.

A diferença entre o realismo e o marxismo é que para o realismo as relações internacionais são relações de disputas e alianças pelo poder entre as nações em um ambiente anárquico, e por isso, a política externa e a política doméstica são esferas de atuação diferenciadas; enquanto defendemos que para o marxismo, a política 
externa e a política doméstica são imbricadas e as relações internacionais são relações de disputa, aliança e interpenetração entre os blocos no poder.

Por isso, nós defendemos que as relações internacionais podem ser pensadas como relações de mútua influência entre os blocos no poder no interior dos mais diferentes Estados.

"[...] Não existe, em realidade, na fase atual do imperialismo, de um lado os fatores externos
agindo puramente do "exterior", e de outro os fatores "internos" "isolados" no seu espaço
próprio [...]". (POULANTZAS, 1976, p. 19).

A reprodução induzida do capital nas diferentes formações sociais estabelece um laço entre as frações endógenas do capital e o capital externo que repercute diretamente na configuração de forças do bloco no poder. Os blocos no poder dos países dependentes se articulam em torno da relação que as frações do capital endógeno estabelecem com o capital imperialista, neste caso, as contradições interimperialistas podem influir em novas configurações de poder no seio do bloco no poder dos países dependentes e também dos demais países imperialistas. Portanto, as relações internacionais são relações entre as classes e frações de classe dos países imperialistas e entre os países dependentes simultaneamente.

Há situações em que uma fração burguesa de um determinado país tem interesse em uma aproximação política ou um acordo comercial com outro Estado com o qual se beneficiaria do mercado para exportação dos seus produtos ou da matéria-prima que poderia importar. Esse interesse pode divergir com outra fração do seu país, ou com uma fração deste segundo Estado, ou até mesmo com uma fração de um terceiro país que tenha o mesmo interesse. Ou seja, a disputa entre frações de classe no âmbito interno e externo se articulam e se chocam ao mesmo tempo. Por isso, a análise das negociações econômicas internacionais ou das coalizões políticas são extremamente complexas, dependem da relação entres os Estados-parte; e da relação entre cada Estado e as classes e frações de classe dentro e fora da formação social nacional.

O instrumental teórico poulantziano também pode "[...] fornecer uma explicação para as mudanças nos rumos da política externa de um determinado país" (AMARAL, 2007, p.134). A mudança de um bloco no poder determinará a mudança da política externa do seu Estado. Sobre isso, concordamos com Gramsci que as “[...] relações internas de um Estado-nação entrelaçam-se com as relações internacionais, criando novas combinações originais e historicamente concretas" (GRAMSCI, 2000, p.42).

Por exemplo, um país agroexportador, cuja burguesia compradora agrária seja dominante, provavelmente, manterá laços fortes com os países imperialistas, entretanto, se a burguesia industrial interna se fortalece no interior do bloco no poder, esta aliança com Estados imperialistas pode não ser mais um privilégio da política internacional deste Estado, levando-o a adotar uma diversificação de parceiros e estratégias de inserção internacional, já que a burguesia hegemônica neste país, não dependerá exclusivamente do acesso ao mercado dos 
países imperialistas para os seus produtos agro-exportáveis e demandará acesso para a exportação dos seus produtos industriais.

Somada a isso, as frações da burguesia podem conflitar em matéria de política exterior. O capital ligado às empresas multinacionais, em um Estado imperialista, pressionará o Estado para uma política externa expansionista, enquanto a fração do capital baseada na acumulação e no mercado interno preferirá uma política mais isolacionista. (POULANTZAS, 1976, p.31). As frações burguesas podem conflitar também em relação à desvalorização da moeda local, abertura comercial, acordos de livre comércio, entre outros.

Em suma, ao desvendar a cena política: a disputa entre as classes e frações de classes e as representações de classe pelos partidos políticos, agentes diplomáticos, comandantes dos exércitos e chefes de governo que podemos entender os reais interesses da atuação internacional de um Estado, já que os Estados atuam externamente e internamente em função da direção política de uma classe ou fração dominante que organiza o bloco no poder.

\section{NICOS POULANTZAS AND SUTUDIES OF INTERNATIONAL RELATIONS}

\section{Abstract:}

This work seeks critically compare the concept of the state used by Hans Morgenthau, acclaimed author of the realist theory of international relations, with the marxist theory of the state systematized by Nicos Poulantzas in Power Politic and Social Classes. We will defend the Marxist concept of the State and other set of problems for the theory of international relations.

Keywords: Marxism; realism; State; social classes; international relations

\section{REFERENCIAS BIBLIOGRÁFICAS}

ALMEIDA, Lúcio Flávio R. Ideologia nacional e nacionalismo. São Paulo: Educ, 1995.

AMARAL, Oswaldo E. O Conceito de bloco no poder e o estudo das relações internacionais. In: Cadernos Cemarx, nº 4. Campinas: Unicamp, IFCH: publicação do Centro de Estudos Marxistas (CEMARX) do Instituto de Filosofia e Ciências Humanas da Universidade Estadual de Campinas, 2007.

\section{ALTHUSSER, Louis. A querela do humanismo. Revista Crítica Marxista. № 9, Ed Xamã, 1999.}

BOBBIO, Norberto. Existe uma doutrina marxista do Estado? In: BOBBIO, Norberto et al. O Marxismo e o Estado. Rio de Janeiro: Graal, 1979. 
126.

As relações internacionais e o marxismo. IN: Ensaios escolhidos. São Paulo: C. H. Cardim, 1988. p.109-

BOITO JR, Armando. Estado, política e classes sociais. São Paulo: Editora Unesp, 2007.

CALLINICOS, Alex. Does capitalism need a state system? Cambridge review of international affairs. Volume 20, $n^{\circ} 4, \operatorname{dez} / 2007$.

CARR, E. H. Vinte anos de crise: uma introdução aos estudos de relações internacionais. Brasília: Editora da Universidade de Brasília e IPRI, 2001.

GRAMSCI, Antônio. Cadernos do Cárcere: Maquiavel - Notas sobre o Estado e a política. Vol. 3. Tradução: Luís Sérgio Henriques, Marco Aurélio Nogueira e Carlos Nelson Coutinho. Rio de Janeiro: Editora Civilização Brasileira, 2000.

HALLIDAY, Fred. Repensando as relações internacionais. Porto Alegre: Ed UFRGS, 1999.

KAUSTKY, Karl. O imperialismo e a guerra. Revista História e luta de classes. Ano 4, edição, no5, Abril 2008.

KEOHANE, Robert O \& Nye, Joseph Jr. Transnational Relations and world politics. 20 edição. Massachusetts: Harvard University Press, 1973.

KRASNER, Stephen D. Defending the national interest: raw materials investments and U. S. foreign policy. Princeton: Princeton University Press, 1978.

LENIN, V.I. Obras escolhidas em três tomos. São Paulo: Editora Alfa Omega, 1982.

LINKLATER, Andrew. Beyond realism and marxism: critical theory and international relations. London: Mc Millan Press, 2001.

MORGHENTAU, Hans J. A política entre as nações - a luta pelo poder e pela paz. Brasília: Editora Universidade de Brasília: Imprensa Oficial do Estado de São Paulo: Instituto de Pesquisa de Relações Internacionais, 2003.

POULANTZAS, Nicos. Poder político e classes sociais. São Paulo: Editora Martins Fontes, 1977.

Crise das ditaduras - Portugal, Grécia, Espanha. Rio de Janeiro: Editora Paz e Terra, 1976.

Classes sociais no capitalismo de hoje. Rio de Janeiro: Zahar Editores, 1978.

ROSENBERG, Justin. The empire of civil society: a critique of the realist theory of international relations. New York/London: Verso, 2001.

WAEVER, Ole, "The Rise and Fall of the Inter-Paradigm Debate." IN: S. Smith, K. Booth, M. Zalewski (eds). International Theory - Positivism and Beyond. Cambridge: Cambridge University Press, 1996.

Trabalho recebido e aprovado em setembro de 2014. 